\title{
Conceptualizing Individual Agency in the Transition from School to Work: A Social-Ecological Developmental Perspective
}

\author{
Ingrid Schoon ${ }^{1,2}$ (1) $\cdot$ Jutta Heckhausen ${ }^{3}$
}

Received: 3 July 2018 / Accepted: 31 January 2019 / Published online: 16 February 2019

(c) The Author(s) 2019

\begin{abstract}
This article addresses the ongoing debate on the role of agency and structure in shaping the transition from school to work. Drawing on theories of life-course sociology and life-span psychology an integrated social-ecological developmental approach is presented, conceptualizing individual agency as a relational and intentional process that evolves through interactions with the wider socio-cultural context. Agency is understood as a multi-dimensional construct, influenced by multiple proximal and distal social circumstances that channel the manifestation of agency by offering distinct transition pathways. The article specifies the ways how social structures support and constrain the development of agency, and asks if individual agency can overcome social constraints, and to what extent and in what circumstances can agency be most effective? It is argued that agency is most influential (a) when social structures are flexible, enabling switching between tracks; (b) during critical windows of opportunity, such as during transitions from one educational track to another or from education into paid employment; (c) in situations when individuals leave a pre-structured path; (d) when intentions are closely matched to individual competencies; and (e) when socio-economic disadvantage is not overpowering. The analysis presented in this paper should enable researchers to expand and deepen their understanding of the role of structure and agency in shaping school-to-work transitions and inform empirical research on the topic.
\end{abstract}

Keywords Agency $\cdot$ Structure $\cdot$ School-to-work transition $($ SWT) $\cdot$ Life course $\cdot$ Expectancy-value theory $\cdot$ Action-phase model

\section{Introduction}

A key developmental task in the lives of adolescents is to prepare for the school-to-work transition, a crucial phase of the life course for young people, which critically affects adult social status attainment and developmental prospects throughout adulthood. This transition generally spans the phase between completion of full-time education or training, the entry into continuous full-time employment, and

Ingrid Schoon

i.schoon@ucl.ac.uk

Jutta Heckhausen

aheckhaus@uci.edu

1 University College London, Institute of Education, 20 Bedford Way, London WC1H OAL, UK

2 Berlin Social Science Centre, Wissenschaftszentrum Berlin (WZB), Berlin, Germany

3 University of California Irvine, 4316 SBSG, Irvine, CA 92697-7085, USA establishing oneself in a career. It can imply a smooth transition leading to a progressing career, or be a most turbulent phase with various attempts to establish oneself in the labor market and in the process moving in and out of jobs, education and training. The transition requires a number of important decisions, such as whether to continue with further education or to leave school directly after completing compulsory education; what kind of job or career to choose; whether to go for an easy-access job that covers basic financial needs or take the route of vocational training or higher education to enter a career with better long-term prospects; and how best to respond to opportunities and constraints in the contemporary labor market. Indeed, individual agency has been identified as a central factor in the study of school-to-work transitions (Dannefer and Huang 2017), in particular regarding issues of status attainment (Eccles 2008; Elder et al. 2015; Schoon and Lyons-Amos 2017) and social mobility (Heckhausen and Shane 2015). For example in a recent UK survey, individual attributes such as confidence, determination and ambition have been identified 
as key drivers for social mobility, enabling individuals to get ahead in life (SuttonTrust 2017). There is, however, a continuing debate about the role of social structure versus individual agency in shaping individual development, highlighting the importance of a fit between societal challenges and individual agency capacities.

Within the psychological literature on individual agency during career transitions concepts such as Protean Career and boundarylessness of individual career striving (Hall 2004) were introduced. These concepts place a strong emphasis on the power of individual self-direction and striving (Briscoe et al. 2006). Within sociology, the idea of a societal development towards individualisation gained prominence (Beck 1992), suggesting that in recent decades individuals are increasingly compelled to make choices throughout their life-course and they are required to take sole responsibility for the consequences of the choices made. However, the notion of unfettered individual agency was challenged, pointing to the persisting societal constraints that continue to shape individual choices and constrain their realization (Johnson and Reynolds 2013; Schoon 2007, 2012). Within sociology, terms such as "structured" or "bounded" agency (Shanahan 2000; Evans 2002) are used to reflect the societal constraints and social embeddedness of individual agency.

Likewise theories on career decision making emphasize the interactions between social structures and individual agency in career pursuit. For example careership theory developed within sociology introduced the term "horizon for action" (Hodkinson and Sparkes 1997), referring to socially structured perceptions about what career options are available and appropriate to strive for. Psychological theories of life design (Savickas et al. 2009) also recognize that an individual's knowledge and identity are the product of social interaction and that meaning is co-constructed through discourse. Although these theories describe how individuals select career goals within structural constraints, their scope is focused on issues related to career counselling. They do not provide a distinct conceptualization of individual agency and how individuals in the context of societal opportunities and constraints engage with or disengage from specific goals. Such an analysis of agency could reveal how an individual's agency develops in interaction with distinct transition pathways that are shaped by the immediate and wider social context.

This article develops an integrated socio-ecological developmental model of agency as manifested in the schoolto-work transition. It is argued that individual agency is a relational process that evolves through interactions with the wider socio-cultural context. Agency is conceptualized as a process of intentional action and action regulation, which operates in the social ecology of opportunities and constraints imposed by social structures and institutions as well as social networks that channel entry, continuation and change in distinct career paths. In this context, distinct processes enabling individuals to steer their lives and potentially overcome social constraints are discussed, as well as the conditions in which agency can be most influential.

\section{Towards a Socio-ecological Approach for the Study of Individual Agency in the School-to-Work Transition}

Drawing on theories developed within life-span developmental psychology and life-course sociology, an integrative social-ecological developmental model of agency is formulated, enabling the examination of the interplay of structure and agency in the school-to-work transition over time and in specific societal contexts. Life-span developmental psychology has long viewed the individual as an active co-producer of development (e.g., Lerner and Busch-Rossnagel 1981). In the past two decades, actiontheoretical and motivational-psychology models have been used to advance the conceptualization of developmental agency (Brandtstädter and Lerner 1999; Freund and Baltes 2000; Heckhausen 1999, 2018). In general terms, there is convergence with life-course sociological constructs of agency (Dannefer and Huang 2017; Elder 1994; Elder et al. 2015) which view agency as an individual-level construct fundamental for social action and choice. However, agency as a non-structural construct has remained an underspecified, "slippery" theoretical concept within sociological research (Fuchs 2001; Hitlin and Elder 2007; Loyal and Barnes 2001). Recently, life-course researchers have included key dimensions of agency based in developmental, motivational and social psychological constructs into their longitudinal research on the transition into adulthood (Hitlin and Johnson 2015; Schoon and LyonsAmos 2016, 2017; Vuolo et al. 2012; see also review in; Settersten and Gannon 2005). These approaches draw on multi-dimensional conceptualizations of agency, as specified within socio-cognitive theories of agency (Bandura 2001, 2006), expectancy-value theory (EVT) (Eccles and Wigfield 2002), the motivational theory of lifespan development (MTD, Heckhausen et al. 2010, 2019) and ecological theories of human development (Bronfenbrenner 1989). These approaches focus on the dynamic interrelations between a changing individual and changing social structures.

The proposed socio-ecological model specifies the multiple influences shaping the development of agency in the transition from school-to-work, ranging from factors in the directly experienced family context (proximal influences), as well as wider societal influences, such as institutional regulations and aspects of socio-historical change. Agency itself is conceptualized as a multi-dimensional construct, 
comprising aspects of expectancy, control perceptions, goal selection and goal setting, intention, volition and goal engagement, control striving, action regulation, disengagement, and goal adjustment that develop during adolescence and young adulthood. It is argued that individual agency cannot be reduced to decontextualized universal principles of psychological functioning, nor to a mere expression of structural constraints or regularities produced by societal institutions or social structures. Agency is understood as a relational construct that emerges through interaction with a wider socio-cultural context. In addition to individual attributes, the characteristics of the wider social context have to be considered-as well as the ways in which individuals interact with this context.

The socio-ecological approach for conceptualizing agency in the school-to-work transitions is outlined in four steps. First, a multi-dimensional conceptualization of the notion of agency as intentional action and action regulation is provided. Second, the societal conditions that shape the opportunities for individual agency during the school-towork transition are described. These are considered as the context of human action, having their effect on the individual through the societal channeling of individual action along distinct pathways. Third, the question if and under which conditions individual agency can overcome societal constraints is asked, identifying key processes that link structure and agency. In particular, a differentiation is made between independent, cumulative, and compensatory processes. Fourth, the circumstances under which agency can be most effective are discussed.

\section{Individual Agency: Intentional Action and Action Regulation}

At the most general level, individual agency is understood as intentional action, i.e. the capability to set goals (i.e. intention), plan their pursuit and attainment in the future (i.e. action planning; foresight), and allow behavior to be guided by goal pursuit (i.e. action-regulation). Moreover, asking what motivates individuals, psychological theories of individual agency have built on the classical expectancyvalue theories (Lewin et al. 1944; Tolman 1932) as applied to achievement motivated behavior (Eccles and Wigfield 2002; Heckhausen and Heckhausen 2018). Expectancyvalue models propose that goal choices and their pursuit are determined by expectancies about the likelihood of attaining the goal and values associated with attaining the goal. The former comprise beliefs about one's own capability, i.e. expectations for success or self-efficacy - the extent to which individuals believe that they can be successful at attaining the specific goal being considered. The latter refer to values associated with attaining the goal, which include values intrinsic to the activity and goal as well as values associated with the consequences of attaining the goal (e.g., social approval, material reward), and the costs one incurs while pursuing it. Values of particular goals such as attaining a university degree or getting into a career, depend on how members of the social community the individual holds in high regard (e.g., parents or the peer group a youth identifies with) view the goal (Eccles and Wigfield 2002).

To comprehensively understand the role of individual agency in the school-to-work transition, it is thus important to consider the multiple components underlying the capability to intentionally select goals. These components include expectancies, values, underlying motive strengths for achievement, power and affiliation. In addition, it is necessary to consider the dynamics of goal pursuit, i.e. the tendency to persist in the face of adversity, the capacity to disengage from futile goals, or to re-engage when the conditions are favorable. Our approach uses the conceptual framework of the Motivational Theory of Lifespan Development (MTD) (for a comprehensive review see Heckhausen and Buchmann 2018; Heckhausen et al. 2010, 2019) which conceptualizes developmental agency in the action field of societal socio-structural and age-graded constraints and comprises an expectancy-value model of goal selection as well as an action-phase model of motivational and volitional self-regulation during goal(re)selection, goal engagement, goal disengagement and re-engagement.

The action-phase model of developmental regulation specifies a set of motivational and volitional phases individuals get involved in as they progress through a developmental action cycle. When first approaching a critical time period for decision making (e.g., during the final year before graduating from school), youth consider alternative possible paths and goals to pursue. During this phase of optimization, individuals are well advised to consider the actual opportunities and constraints as well as the consequences of choosing one or another path. After an individual has made a choice and thus passed the decisional Rubicon, it is most adaptive to stop pondering pros and cons of alternatives, but instead invest full throttle into the chosen path. This is particularly true under difficult conditions, for example when job or training opportunities are scarce. Under such conditions of threatened yet urgent goal pursuit, individuals may need to use extra meta-volitional strategies to keep themselves committed and focused. In addition, it may be advantageous to think out-of-the-box and come up with compensatory means of getting extra help from others or using detours or unusual means. We will come back to this later.

If these enhanced means of goal engagement fail, individuals may need to adjust their goals (e.g., look for a different or less prestigious apprenticeship, enroll for a different program of studies, or hope to get accepted at a later time point)—or even give up certain goals altogether (e.g., if certain options hold no prospects). Indeed, under circumstances 
of high opportunity costs, that is when alternative goal engagements are time sensitive, decisive goal disengagement is essential to cut one's losses with the futile goal pursuit and move on to a more realistic goal before it is too late (Tomasik and Salmela-Aro 2012). Thus goal engagement and disengagement has to be synchronized with available opportunity structures.

\section{Societal Canalization of the School-to-Work Transition}

Societies vary regarding the opportunity structures and support they provide to young people engaging in the school-towork transition, variations which have been conceptualized by the term societal channeling or canalization (Heckhausen and Buchmann 2018). The wider socio-historical context, institutional arrangements and social inequality at the family level all play a role in shaping the contours of the life course, setting up the potential pathways for individuals to aspire to and to follow, specifying relevant requirements for achievement and defining key deadlines to do so (Buchmann and Steinhoff 2017; Heckhausen et al. 2010, 2019; Schoon and Bynner 2017; Wrosch and Heckhausen 1999). Transition experiences are largely shaped by opportunities and constraints presented by the socio-historical context and economic conditions, and within this context are dependent on individual decision making and agency.

\section{Historical Context}

The wider socio-historical context refers to the overall economic circumstances (e.g., boom or bust), the cultural climate or current "Zeitgeist" (i.e. ideas and beliefs relevant at the time), or political settings (e.g., collective versus individualistic orientations, periods of stability versus rapid social change) that shape available transition pathways. Generally, over the past four decades most Western countries have witnessed dramatic changes in employment opportunities following the introduction of new technologies, the disappearance of manual jobs, the increasing participation of women in the labor market (Blossfeld et al. 2005), the gradual shift towards automatization and increasing precariousness of transitions (Ashton 2017; Bell and Blanchflower 2011; Schoon and Bynner 2019). As a consequence of massive restructuring and changes in the labour market since the 1980s, there has been increasing fragmentation, uncertainty and unpredictability regarding employment careers, and that in turn required increased individual agency in proactively shaping one's career (Heckhausen 2010; Schoon 2007).

Most developed countries have responded to the economic changes by placing greater emphasis on participation in education and training, to equip young people with the necessary skills for making the transition into the world of work. Increasing numbers of young people participated in higher education, including those from relatively disadvantaged social backgrounds (Blossfeld et al. 2005; Schoon and Bynner 2017). The observation of extended education participation, often until the mid or late $20 \mathrm{~s}$, stimulated the introduction of the term "emerging adulthood" (Arnett 2000) as a synonym for a new, universal developmental period, characterized by identity exploration and delay of responsibility. However, the assumption of emerging adulthood solely based on intentional choice, does not take into account the role of socio-historical and economic conditions that produce the setting for extended transitions.

For example, in most developed countries, the number and proportion of full-time employees with contracts of indeterminate duration has decreased constantly since the mid 1980s, unemployment rates and the proportion of insecure jobs including "zero hours contracts" and precarious employment is growing even among graduates (Standing 2011; Schoon and Bynner 2019). The 2008 Great Recession added another blow. Young people have been hit particularly hard by this downturn, as unemployment and flexible employment among the young (under 25 years) is generally higher than average (Bell and Blanchflower 2011; Blossfeld et al. 2005). These developments prolonged the step into financial independence and brought with them a prolonged dependence on parents for financial, social and emotional support (Schoon and Bynner 2017). There were, however, country-specific variations in the extent to which young people were affected by the economic downturn, associated with different "transition regimes" or "institutional filters", such as regulations regarding opportunities for employment, education and training (Schoon and Bynner 2019).

\section{Social Institutions and Transition Regimes}

Different societies provide different sets of possible pathways for the school-to-work transition, along with their institutional support systems. These pathways generate the main "action field" for young people to find their way in. Given pathways are partially age-graded, e.g., regarding variations in legal age of entering and leaving full-time education and paid employment, and are regulated by social institutions based on cultural beliefs and social norms about age-appropriate behavior, timing, and sequencing of social roles or status (Blossfeld et al. 2005; Buchmann and Kriesi 2011; Heckhausen and Buchmann 2018). Institutional regulations regarding the school-to-work transition are also referred to as "transition regimes" (Raffe 2008; Walther 2006; Schoon and Bynner 2019), or "institutional filters" (Blossfeld et al. 2005), reflecting the relative enduring features of a country's institutional and policy arrangements, including the structure of education and training systems, features of employment regulation, social welfare systems and the assumptions 
underlying youth policy regulating transition patterns. For example, building on Esping-Andersen's (1990) model of welfare regimes Walther (2006) differentiates between subprotective, universalistic, liberal, and employment centered transition regimes. This differentiation has been highly influential in European comparative youth research, yet more recent approaches have advanced a "welfare mix" approach, to clarify the different contributions made by the state, the family and the labor market in supporting young people's school-to-work transitions (Antonucci et al. 2014).

The sub-protective transition regime applies primarily to southern European countries, such as Spain, Portugal, Italy, or Greece. These countries are characterized by a high share of informal or insecure employment conditions and the lack of a comprehensive social safety net. Education is mostly comprehensive, although with relatively high rates of early school leaving (i.e. below upper secondary qualifications) (Eurostat 2017). Vocational training is not well developed, nor highly valued, mainly provided by professional schools and the involvement of companies is low. Due to the economic weakness of many regions, there are high rates of youth unemployment (Schoon and Bynner 2019), prolonged periods of job search and a long waiting phase during which young people depend primarily on their families for support.

Universalistic transition regimes, prevalent in Scandinavian countries such as Sweden, Norway or Finland are characterized by a comprehensive and inclusive education system with diversified post-compulsory routes into general and vocational education and high levels of investment in tertiary education. Many students combine work and study, smoothing the transition to employment (Eurofound 2013). The employment system is typified by an extended public sector and a strong emphasis on equal opportunities. Collective agreements constitute important driving forces for labor market regulations, wage setting and social assistance programs. Counselling is widely institutionalized at all stages of education, training, and the transition to employment, aiming to identify individual motivation and support personal development. Young people have the right to social assistance from 18 years onward, regardless of the socioeconomic status of their families. If they are participating in either formal education or training they receive an educational allowance.

The liberal transition regime, predominant in Anglophone countries, such as the UK and the USA, is characterized by a comprehensive education system, as well as high flexibility and fragmentation in post-compulsory education. It values individual rights and responsibilities more than collective provisions. The labor market is largely deregulated with a large segment of low-skilled and non-standard jobs, and checkered attempts to establish a vocational training system. Vocational training is mostly focused on delivering particular occupational skills, albeit with relative low quality standards. The poor quality of much of the work-based training available to teenagers, and low credibility of the certification arising from it, has yet to convince employers and families that apprenticeship is a high value alternative to staying on in academic education. For example, youth in the US face a system that provides no structured path into skilled employment without college, strongly favoring college education as a prerequisite for any worthwhile occupational career (Heckhausen and Shane 2015). Attempts to introduce what are described as non- or applied baccalaureate level programs (i.e. non-college bound youth) have so far not succeeded in creating opportunities for a smooth school-to-work transition (Dougherty and Lombardi 2016).

Employment-centered transition regimes are typical for Germany (and most German speaking countries including Austria and Switzerland). Education is organized more selectively, allocating young people to occupational careers and associated social position at an early age. For example, in Germany young people are channeled into different tracks leading to low-skilled occupations, skilled vocational careers requiring apprenticeships, and professional careers requiring university degrees. By the age of 10 most pupils in Germany are selected into one of these three tracks. It is possible to switch tracks, yet that is not a very easy route to take (Hillmert and Jacob 2010). Vocational training plays a central role and is relatively standardized. It is mostly company based, involving a "social partnership" comprising local government, vocation-oriented schools (i.e., Berufsschule), employers' organizations, and trade unions in maintaining and reforming the apprenticeship pathways, with a direct link to the employment system.

Where did young people fare best in the aftermath of the 2008 recession? A central purpose in the specification of "transition regimes" is to identify features of "successful" transition systems, which enable a smooth integration into the labor market (Raffe 2008). Generally, the labor-market integration of new entrants tends to be faster in countries characterized by strong institutional linkages between education and the labor market, and strong institutional networks which can support transitions from education to work. And indeed, employment focused countries, such as Austria, Germany, the Netherlands and Switzerland have been most successful in keeping young people engaged in the labor market with youth unemployment rates mostly stayed around $10 \%$ (Schoon and Bynner 2019; OECD 2019). This was mostly due to the efficient use of vocational training programs and well-organized pathways that connect initial education with work and further study, but also due to a strong economy and robust employment protection regulations. Youth coming of age in countries with a sub-protective transition regime (e.g., Spain, Greece and Portugal) have been hit hardest by the 2008 recession, suffering the highest levels of youth unemployment (between 30 and 55\%), and high levels of 
temporary employment. Employment opportunities for young people in countries with a liberal or a universalistic transition regime were less severely affected, yet unemployment rates reached over 30\% in Ireland, and around 20\% in the UK and the US. Finland and Sweden, representatives of a universalistic transition regime, also suffered high youth unemployment rates (over 20\%). At times when there is exceptional economic strain, the institutions concerned with managing the education and training system of any country become the key agents of social policy concerned with ensuring that young people have opportunities to participate and engage in society. In particular, clear pathways between the education system and the labor market play an important role in buffering the negative effect of the recession on employment prospects, and outline a transparent path of choices and required behaviors for young people to follow (Schoon and Bynner 2017, 2019).

\section{Social Stratification}

In addition to institutional arrangements offering distinct transition pathways, the social structure of a given society regulates access to these pathways through the influence of social status on material, cultural and social resources, and the "horizon of perceived possibilities" (i.e. the perception about what career options are available and appropriate to strive for). Even though most modern societies uphold an ideal of equal life chances for everyone, each of them provides SES-differential landscapes for pursuing major developmental goals regarding education and career development (Heckhausen and Buchmann 2018). Indeed, a range of indicators of family SES, including parental education, occupational status and income are associated with young people's education and employment aspirations and subsequent experiences in the education system and labor market. Parents in a higher social position generally have more access to financial resources which enable them to inspire and support the aspirations of their offspring by purchasing study materials or tutoring or even simply providing them with a room or desk to study, financing their extended education participation and associated tuition and living costs, or supporting them through unpaid internships or volunteering to acquire relevant skills and competencies. Moreover, highSES parents might have the relevant cultural knowledge of how different institutions work, facilitating negotiations with gate keepers and handling institutional requirements, and they have connections to social networks facilitating access to important information and contacts. Thus, young people from the most privileged backgrounds tend to have higher level resources and ambitions than their less privileged peers (Eccles 2008; Schoon 2010, 2014).

There have, however, been significant changes regarding the association between parental socio-economic background and young people's ambitions in the aftermath of the massive education expansion and changing employment opportunities described above. In the course of this social change, individuals independent of their social background were encouraged to raise their achievement orientation and ambitions for upward social mobility. Increasingly young people from disadvantaged background aspire to go to university and to enter a professional career, thus climbing the social ladder (Reynolds and Johnson 2011; Schoon 2010, 2012; Shane and Heckhausen 2013), in particular young women and those from ethnic minority background (Schoon and Lyons-Amos 2017). Indeed, a new norm of "college for all" (Rosenbaum 2001) has been emerging, encouraging high education expectations regardless of academic aptitude or social background. Currently, most young people in the Global North are striving to obtain a college degree qualification, and the association between parental socio-economic status and achievement orientations has weakened (Johnson and Reynolds 2013; Reynolds and Johnson 2011; Schoon 2010, 2012). Within a context of education systems that encourage and facilitate upward mobility from lower to higher-level college institutions (e.g., California Master Plan for Higher Education), young people from a less privileged background who have high long-term educational aspirations are more likely to succeed regarding educational and occupational attainment than their less ambitious peers (Heckhausen and Chang 2009; Schoon and Lyons-Amos 2016, 2017). A potentially important motivator for such high educational aspirations is that current cohorts of young people will need higher levels of educational qualifications to avoid downward social mobility and maintain the social status of their parents, never mind moving up the social ladder (Schoon and Bynner 2017).

\section{How Societal Landscapes of Opportunity Support and Constrain the Development of Individual Agency}

Countries provide different institutionalized pathways that stratify individuals' lives into path-dependent trajectories leading to very distinct outcomes. The different pathways offer a number of sequentially organized decision points that require individuals to make choices. For example, after the completion of compulsory education young people have to choose whether to continue in further and higher education or whether to enter paid employment, either with or without training. The transition from school-to-work occurs during certain critical windows of age timing, offering optimal opportunities as well maximum risks during those age periods. Choosing one particular path over another can influence later outcomes, a process also referred to as "path dependency". For example, while staying on in education is associated with higher qualification and better job prospects, early school leaving without relevant qualifications is often 
associated with less advantaged employment opportunities, and makes it more difficult for the individual to return to education at a later time point. On-time transitions are made easy, whereas off-time transitions are difficult for the individual to achieve. However, there is also potential for change in direction, and especially at decision points, small differences pertaining to or acting on the developing individual agents can guide them into one developmental path, moving away from alternative paths. For example, at critical decisions points an external push (e.g., by an economic crisis) or alternatively an internal impetus (e.g., raised aspirations) can shift the individual into a developmental trajectory far removed from the original path or trajectory.

We can use the ideas of Kurt Lewin about the hodological (i.e., path-related) characteristics of action fields (Lewin 1943) to understand how societal structuring and cultural norms about the life course shape the individual's development of directed motivation and behavior. We can consider the life course as a field of action, in which the individual's position may be adjacent or further away from a desired goal state, including Lewin's notion that an environmental field may involve the necessity of detours to reach a certain goal, when direct access to an adjacent field is blocked. Applying Lewin action field model to the life course, requires the addition of a temporal dimension to Lewin's hodological conceptions (see also Levy and Bühlmann 2016). Depending on the hodological and temporal distance of a present state to the desired developmental goal, the incentive of the ultimate goal may or may not be sufficient to motivate an individual agent to actively pursue it. Moreover, and as a function of socio-economic fit with the desired goal, more or less elaborate and rich personal and social resources may be required for the individual agent to pursue the goal through the more or less easily navigated life-course action field. For example, for students early in secondary education, the incentive pull of admission to a highly prestigious college, may be too far away to motivate intense academic effort, so that parental pressure or relevant career guidance can make more of a difference. Action paths towards developmental goals that involve several steps and cover extended periods of life time are particularly challenging for the individual and her/his regulatory efforts, unless they are supported by institutional structures, such as educational institutions with strong normative pressure to stay on track. Considering this, it is clear that individuals who cannot use such institutional supports because they are trying to achieve certain developmental attainments outside the well-scaffolded paths and/or at a non-normative time in life, can be successful only if they command special and strong self-regulatory motivational skills to overcome adversity, stay committed and focused on giving the chosen goal priority over any competing goals or activities, or get lucky. Under circumstances that make social mobility outside or inside the well-established paths impossible, individual agents need to be able to know when it is time to disengage from a futile endeavor and revise their goals and plans for the future.

In sum, the processes shaping transition experiences of young people are multifaceted, including macroeconomic conditions, institutional structures, social background, gender, ethnicity, as well as individual resources such as ability, motivation, and aspirations and their development over time. For a better understanding of transition experiences of young people it is important to consider the relational nature, the dynamic interplay between structural constraints and individual agency and how these might differ and change over time and across socio-cultural contexts.

\section{Can Individual Agency Overcome Social Constraints?}

Being active agents in their own life course, individuals can make use of the opportunities and flexibilities in a given society when navigating a life-course transition, such as the one from school to work. Although educational and occupational attainment is shaped by family socio-economic background and resources, as reflected in the term of "bounded or structured agency" (Evans 2002; Shanahan 2000), individuals from very similar backgrounds can end up in quite different positions in society when they reach adulthood. A growing body of evidence points to the significant role of so-called "non-cognitive" skills, including motivational characteristics such as goal-setting, control perceptions, and self-regulation, in moderating the impact of socio-economic disadvantage. These individual-level skills and competencies can become critical resources for attaining academic, social, health and employment outcomes in addition and beyond the established predictors of status attainment, such as cognitive ability and parents' socio-economic position (Heckman and Kautz 2012; OECD 2015).

The concept of "non-cognitive skills" was introduced by sociologists Bowles and Gintis (1976) as a catch-all phrase to distinguish factors other than those measured by cognitive test scores such as literacy and numeracy. There is, however, no common definition of the relevant skills and competences, and the concept of "non-cognitive skills" is used as a "black box" comprising multiple competences, including decision making, self-regulation, problem solving, creative thinking, effective communication, interpersonal relationship skills, self-awareness, coping with stress, as well as broader indicators of personality (e.g., conscientiousness, Heckman and Kautz 2012). The effectiveness of these characteristics in facilitating individuals to overcome disadvantages in the school-to-work transition are, however, likely to differ across cultures and settings, and across different domains of application, because the specific challenges in these social settings can differ a lot. Depending on the specific challenges in a given society at a specific life-course 
transition, certain skills and competencies may be more important than others. For a more comprehensive understanding of how and under what circumstances different individual competencies are effective, the black box needs to be unpacked. Here we focus on the role of individual agency, understood as a multi-dimensional construct. In particular, we focus on aspects of the value systems (intrinsic, extrinsic; costs; Eccles and Wigfield 2002; see for example education-career trade-offs in Heckhausen et al. 2013), aspirations and expectations about goal controllability and one's self-efficacy to attain goals (Schoon and Lyons-Amos 2017; Schoon and Mortimer 2017), and about the consequences of goal attainment for other goals and life domains, goal commitment and engagement, volitional self-regulation (Shane and Heckhausen 2012, 2016; Shane and Heckhausen 2013), and the ability to adjust goals or even disengage from goals if needed (see Heckhausen and Wrosch 2016).

When considering the potential compensatory role of agency-related capacities with regard to the effects of social origin on ultimate social status attained in adulthood, previous social science research has identified three different processes involving independent, cumulative, and compensatory effects (Damian et al. 2015; Ng-Knight and Schoon 2017; Shanahan et al. 2014; Schoon and Lyons-Amos 2017). The evidence so far is focused on the role of broad personality indicators (not discussed here), with some evidence also being available regarding the role of intentions, expectations and values, which are summarized here. However, further evidence is needed to complete the picture (especially regarding the role of values and the relative importance and possible interactions between different agency indicators).

\section{Independent Effects}

Findings from research examining the predictive power of educational or occupational aspirations, self-efficacy and self-regulation on outcomes such as educational and occupational attainment show that major dimensions of agency have a unique and significant contribution on attainment outcomes beyond the influence of cognitive ability and family socio-economic background (SES). For example, achievement goals, such as aspirations to participate in further and higher education or to enter a professional career are associated with subsequent educational (Domina et al. 2011; Villarreal et al. 2015; Reynolds and Johnson 2011) and occupational attainment, over and above the influence of social background and cognitive ability (Johnson and Reynolds 2013; Reynolds et al. 2007; Schoon and Polek 2011), as are subjective expectations of success (Ashby and Schoon 2010; Hitlin and Johnson 2015) and indicators of self-regulation and self-efficacy (Moffitt et al. 2011; Ng-Knight and Schoon 2017).
Although the ideologically enhanced "social mobility dream" does not generally match actual mobility (Heckhausen and Shane 2015; Schoon and Mortimer 2017), it nonetheless can steer individuals to strive for it. A longitudinal study of US youth transitioning out of high school found that control-related beliefs about the controllable dimensions of effort and social connections, but not beliefs about uncontrollable dimensions such as ability or luck, were predictive of career-related control striving 1 year later, and in turn career striving amplified personal control beliefs (Shane and Heckhausen 2012, 2013). In a study with university students transitioning into work life, Shane and Heckhausen (2016) found two contrasting belief-patterns about career development, one that emphasized the role of individual merit (effort and ability) and one that focused on the role of external factors outside on individual's control (privilege and luck). The meritocratically oriented group of youth were more engaged with their career goals and also reported better career progress. The group viewing external factors as most prominent were more likely to disengage from and to devalue their career goals. Another study showed that meritocratic beliefs about one's own career-related agency, but not about career-related agency for most other people were associated with career outcomes (Shane and Heckhausen 2013). In assessing "independent" effects, it has however to be considered that indicators of agency are already shaped by socio-economic factors, and if the association between them is substantial there is the potential of over-estimating individual differences of youth that are partially due to SESrelated advantages and class-specific socialization.

\section{Cumulative Effects}

Cumulative processes reflect the fact that an advantaged social position is associated with resources critical for further relative gains in position, such as high aspirations as well as access to financial, social and cultural resources that provide advantages in negotiating socially structured transition pathways, while a disadvantaged position comes with accumulated detrimental effects of insufficient resources. For example, young people from the most privileged backgrounds tend to have higher levels of ambition than their less privileged peers, while those from relatively disadvantaged backgrounds are facing greater difficulties when developing ambitious educational and career goals, because they tend to feel constrained by perceptions of limited opportunities and resources (Eccles 2008; Schoon 2007). Their "horizon of perceived possibilities" is foreshortened, and thus they end up expressing lower educational and occupational aspirations and self-confidence than their more privileged peers (Duckworth and Schoon 2012; Eccles 2008; Mortimer 2003; Schoon 2012), and are more likely to believe that external causal factors (i.e. other people, luck or fate) influence their 
success in society (Shane and Heckhausen 2013). Even after taking into account early academic attainment, lower SES youth are less likely to achieve higher level academic qualifications and top-level jobs characterized by high pay, job security and autonomy, and are more likely to experience precarious employment (Schoon and Lyons-Amos 2016, 2017). Thus, (dis)advantages tend to accumulate over the life course (DiPrete and Eirich 2006; Schoon et al. 2002) favoring certain more-advantageous trajectories for upper class individuals and other less advantageous trajectories for lower class individuals. Moreover, differences between individuals become amplified along a given transition pathway, so that the outcomes are much more disparate than the original states.

\section{Compensatory Effects}

Potential compensatory effects, also described by the term "resource substitution" (Ross and Mirowsky 2006), refer to processes where one resource can substitute for another or can fill the gap if the other is absent. The "resource substitution" hypothesis predicts the worst outcomes for those with neither resource. Within compensatory effects, we can differentiate whether overcoming a given adversity requires only one dimension of agentic capacity (e.g., very high ambitions or very high self-regulatory skills) or multiple dimensions (e.g., high ambitions, high self-regulatory skills, high success expectations and high levels of self-efficacy). The former constellation is one of multiple sufficient causes whereas the latter is reflecting multiple necessary causes.

Evidence regarding potential compensatory effects of agency suggests a mixed picture and is not clear cut. Although findings within the UK context suggest that high aspirations among relative disadvantaged students enable them to do better than their less ambitious peers from a similar background (Schoon and Parsons 2002; Schoon and Polek 2011; Schoon 2014), educational attainment is at least as strong, if not a stronger predictor of career attainment than individual aspirations. This is especially the case for young people born in later cohorts, who made the schoolto-work transition after the expansion of higher education in the late 1980s (Duckworth and Schoon 2012; Schoon 2007, 2012). Compensatory effects of individual agency were evident in studies examining the effect of the Great Recession on young people making the transition from school-to-work. When young people held onto a more positive outlook for the future, their parents' economic troubles posed less risk to their socioeconomic functioning as young adults (Mortimer et al. 2014; Vuolo et al. 2012). Even among young people growing up with unemployed parents (Schoon 2014), high levels of academic achievement orientations were associated with a reduction in the time spend not being in education, employment or training (NEET). Similar buffering effects were observed for young people maintaining high levels of control perceptions in situations of family socio-economic adversity, although control perceptions could not provide protection against long-term inactivity that is being more than 6 months NEET (Ng-Knight and Schoon 2017).

However, young people from higher socioeconomic status families were more likely to hold onto their high education expectations then their less privileged peers, and these more persistent high expectations might help explain the greater success of young people from higher socioeconomic status backgrounds in earning a 4-year degree (Johnson and Reynolds 2013). In addition, parental resources, in particular parental education can buffer the effect of economic hardship, and in an interesting twist to the story there is evidence to suggest that the academic orientations of parents back when they had been adolescents themselves, appeared to be protecting their children from the risks of economic troubles many years later (Mortimer et al. 2014). These findings drive home the fact that individuals may react to the same situation in very different ways, that individuals tend to hang on to their hopes and dreams even in times of adversity unless socio-economic conditions are overpowering their ability to cope, or changing circumstances require them to change the course of their action and the associated aspirations.

\section{To What Extent and Under Which Circumstances can Agency be Most Effective?}

Potential advantages of agency-related individual capacities vary across cultural contexts and appear to be especially prevalent in societies with a relatively flexible transition system that allows for individual variations in paths to successful adult careers, as for example in the USA and the UK. In other more stratified societies, such as the German system of early educational segregation into different school types and highly institutionalized vocational training, such individual optimizations are less needed and less enabled (Evans 2002; Heckhausen and Chang 2009; Holtmann et al. 2017). We thus have to ask, what are the characteristics of a socio-structural framework that permit individual agency to be effective and enable young people from disadvantaged background to succeed?

First, individual agency is not uniformly effective throughout the life course. It is less needed when individuals move on well-buffered and institutionally regulated paths, i.e. during primary and secondary school, after having decided for a study major (Heckhausen 2010; Heckhausen and Shane 2015), or when entering a well-supported vocational training program leading to relatively stable vocational careers. Individual agency is most needed at times of transition, when individuals leave a pre-structured path, 
such as at the end of compulsory schooling, when they enter a new path or field and are assuming new social roles.

Second, there are crucial "windows of opportunity" when agency is most effective. These are related to the appropriate age-related timing of transitions. For example, educational systems relying on strong and early-ability tracking tend to foreclose or open up subsequent educational opportunities at the respective transition points. Due to the channeling of educational trajectories based on early decisions, early manifestations of agency may potentially be more decisive than later ones (Buchmann and Steinhoff 2017). Moreover, engagement with a developmental goal can become urgent when facing rapidly declining opportunities (i.e., developmental deadlines; Heckhausen et al. 2010, 2019), such as access to stipends or funding for distinct educational or career openings. Once opportunities decline, required investments to achieve these goals become too costly, and individuals need to disengage from obsolete or futile goals and refocus on goals that are still attainable (Heckhausen et al. 2010). Sticking with unobtainable goals can become maladaptive, especially when individuals persist despite repeated set-backs, feeling entrapped in a project that does not yield the anticipated outcomes. This situation has been termed "action crisis" (Brandstätter and Herrmann 2016) describing the conflict of being torn between holding on giving up a specific goal.

Third, agency is facilitated in conditions where the action field is more permeable, i.e. the boundaries between different tracks or path are not too strict and it is possible to change between tracks. Ideally such permeability could be facilitated by the building of bridges and flexibility in changing track (Heckhausen 2010; Heckhausen and Shane 2015; Schoon 2015). This would be the case in institutions that enable change between educational or occupational tracks, not only at the beginning but also at multiple crossover points. As we have described previously, in some countries, such as Germany, students can become "locked" into tracks offering different learning opportunities and subsequent differential path-dependent career chances. Although these pathways facilitate a smooth transition from school to work, there can be the danger that being locked into a rigid and inflexible system can undermine individual agency, in particular via detrimental effects on self-concepts and control beliefs (Chmielewski et al. 2013; Dumont et al. 2017; Marsh et al. 2007; Steinhoff and Buchmann 2017). In contrast, in countries with more flexible and permeable transition systems, such as the UK or the US, high levels of agency are required to navigate a complex action field (Evans 2002; Heckhausen and Chang 2009).

Fourth, access to socio-economic resources, which in turn is shaped by social background, determines the extent to which agency can be mobilized and realized. Agency is less effective in situations where the socio-economic risks are over-powering (Duckworth and Schoon 2012; Ng-Knight and Schoon 2017). Parents in higher social positions generally have more access to financial, cultural and social resources that enable them to support the aspirations of their offspring (Evans 2002; Shanahan 2000; Schoon and Parsons 2002; Schoon 2010, 2012). There might however also be the danger of intergenerational path dependency, where young people feel pushed to pursue the ambitions and aspirations of their parents and are not enabled to express or follow their own dreams and ambitions (Franceschelli et al. 2016).

Fifth, there is a potential "dark side" to high levels of agency beliefs. For example, there is evidence to suggest that unrealistic ambitions can harm individuals by promoting inappropriate persistence and overconfidence, which in turn hinder performance and attainment (Armor and Taylor 1998; Salmela-Aro 2017; Schoon and Lyons-Amos 2017). This is particularly the case in situations where the demands of the task are higher than individual capabilities, or where agency beliefs are not matched to individual competencies. There are however also variations by sociocultural context. For example, the less structured and more permeable educational system of the USA provides better opportunities for highly ambitious students than the highly structured education system in Germany, where educational aspirations need to be closely calibrated to one's social status and prior school achievement (Heckhausen and Chang 2009).

\section{Conclusion}

Integrating assumptions developed in life course sociology and life span psychology, this paper presents an integrative socio-ecological developmental model for studying the interplay of structure and agency in the transition from school-to-work. Agency cannot be comprehensively conceptualized as a sheer individual level construct, nor as the mere reproduction of existing social structures. The manifestation of agency is a relational and intentional process that emerges through person-context interactions over time and in context. The development and realization of individual agency is shaped by social structures and networks that constrain, extend, and also enable the formation of new expressions of agency. In their transition from school to work young people carve their pathways based on the competencies, resources, and structural opportunities they perceive to be available to them. They have to develop and specify their intentions and translate them into action in order to pursue and achieve, or revise them, in a given social context. Individual agency can to some limited extent compensate the consequences and experience of socio-economic adversity. Yet, individuals 
and context are co-constitutive and individuals cannot succeed without the availability of viable career pathways and opportunities enabling them to make appropriate decisions, access to safety nets to catch those who fall off track, and springboards encouraging new starts and initiative when things do not go as planned. The proposed socio-ecological approach facilitates a better understanding and empirical conceptualization of the development and manifestation of agency in the school-to-work transition.

Acknowledgements The first draft of this manuscript was written while both authors were visiting scientists at the Berlin Social Science Center (WZB) during September/October 2017.

Authors' Contribution IS and JH jointly conceived and drafted the article, with IS completing a greater portion of the draft and coordinating the submission. Both authors read and approved the final manuscript.

Funding Both authors thank the Berlin Social Science Centre (WZB) for enabling and supporting the collaboration. IS also acknowledges support from the British Economic and Social Research Council (ESRC), Grant number ES/J019135/1 for the Centre for Learning and Life-chances in the Knowledge Economies (LLAKES, Phase II).

\section{Compliance with Ethical Standards}

Conflict of interest The authors report no conflict of interest.

Open Access This article is distributed under the terms of the Creative Commons Attribution 4.0 International License (http://creativeco mmons.org/licenses/by/4.0/), which permits unrestricted use, distribution, and reproduction in any medium, provided you give appropriate credit to the original author(s) and the source, provide a link to the Creative Commons license, and indicate if changes were made.

\section{References}

Antonucci, L., Hamilton, M., \& Roberts, S. (Eds.). (2014). Young people and social policy in Europe. Dealing with risk, inequality and precarity in times of crisis. Basingstoke: Palgrave Macmillan.

Armor, D. A., \& Taylor, S. E. (1998). Situated optimism: Specific outcome expectancies and self-regulation. In M. P. Zanna (Ed.), Advances in experimental social psychology (Vol. 30, pp. 309379). San Diego, CA: Academic Press.

Arnett, J. J. (2000). Emerging adulthood. A theory of development from the late teens to the late twenties. American Psychologist, 55(5), 469-480.

Ashby, J. S., \& Schoon, I. (2010). Career success: The role of teenage career aspirations, ambition value and gender in predicting adult social status and earnings. Journal of Vocational Behavior, 77(3), 350-360. https://doi.org/10.1016/j.jvb.2010.06.006.

Ashton, D. (2017). Globalization and its impact on the political, economic, and labor market aspects of the youth transition. In I. Schoon \& J. Bynner (Eds.), Young people's development and the Great Recession: Uncertain transitions and precarious futures. Cambridge: Cambridge University Press.

Bandura, A. (2001). Social cognitive theory: An agentic perspective. Annual Review of Psychology, 52, 1-26. https://doi.org/10.1146/ annurev.psych.52.1.1.
Bandura, A. (2006). Toward a psychology of human agency. Perspectives on Psychological Science, 1, 164-180.

Beck, U. (1992). Risk society. Towards a new modernity. London: Sage.

Bell, D. N. F., \& Blanchflower, D. G. (2011). Young people and the Great Recession. Oxford Review of Economic Policy, 27(2), 241-267. https://doi.org/10.1093/oxrep/grr011.

Blossfeld, H.-P., Klijzing, E., Mills, M., \& Kurz, L. (2005). Globalization, uncertainty, and youth in society. London: Routledge.

Bowles, S., \& Gintis, H. (1976). Schooling in capitalist America (Vol. 75). New York: Basic Books.

Brandstätter, V., \& Herrmann, M. (2016). Goal disengagement in emerging adulthood: The adaptive potential of action crises. International Journal of Behavioral Development, 40(2), 117125. https://doi.org/10.1177/0165025415597550.

Brandtstädter, J., \& Lerner, R. (1999). Action and self-development: Theory and research through the life span. London: Sage.

Briscoe, J. P., Hall, D. T., \& DeMuth, R. L. F. (2006). Protean and boundaryless careers: An empirical exploration. Journal of Vocational Behavior, 69(1), 30-47. https://doi.org/10.1016/j. jvb.2005.09.003.

Bronfenbrenner, U. (1989). Ecological systems theory. In R. Vasta (Ed.), Six theories of child development: Revised formulations and current issues (pp. 187-250). Greenwich: JAI Press.

Buchmann, M., \& Steinhoff, A. (2017). Co-development of student agency components and its impact on educational attainmenttheoretical and methodological considerations introduction. Research in Human Development, 14(2), 96-105. https://doi. org/10.1080/15427609.2017.1305818.

Buchmann, M. C., \& Kriesi, I. (2011). Transition to adulthood in Europe. Annual Review of Sociology, 37(37), 481-503.

Chmielewski, A. K., Dumont, H., \& Trautwein, U. (2013). Tracking effects depend on tracking type: An international comparison of students' mathematics self-concept. American Educational Research Journal, 50(5), 925-957. https://doi.org/10.3102/00028 31213489843.

Damian, R. I., Su, R., Shanahan, M., Trautwein, U., \& Roberts, B. W. (2015). Can personality traits and intelligence compensate for background disadvantage? Predicting status attainment in adulthood. Journal of Personality and Social Psychology, 109(3), 473-489. https://doi.org/10.1037/pspp0000024.

Dannefer, D., \& Huang, W. (2017). Precarity, inequality, and the problem of agency in the study of the life course. Innovation in Aging, 1(3), 1-10. https://doi.org/10.1093/geroni/igx027.

DiPrete, T. A., \& Eirich, G. M. (2006). Cumulative advantage as a mechanism for inequality: A review of theoretical and empirical developments. Annual Review of Sociology, 32, 271-297 (Palo Alto: Annual Reviews).

Domina, T., Conley, A., \& Farkas, G. (2011). The link between educational expectations and effort in the college-for-all era. Sociology of Education, 84(2), 93-112. https://doi.org/10.1177/19414 06411401808.

Dougherty, S. M., \& Lombardi, A. R. (2016). From vocational education to career readiness. The ongoing work of linking education and the labor market. Review of Research in Education, 40(1), 326-355. https://doi.org/10.3102/0091732X16678602.

Duckworth, K., \& Schoon, I. (2012). Beating the odds: Exploring the impact of social risk on young people's school-to-work transitions during recession in the UK. National Institute Economic Review, 222, 38-51.

Dumont, H., Protsch, P., Jansen, M., \& Becker, M. (2017). Fish swimming into the ocean: How tracking relates to students' self-beliefs and school disengagement at the end of schooling. Journal of Educational Psychology, 109(6), 855-870. https://doi. org/10.1037/edu0000175. 
Eccles, J. S. (2008). Agency and structure in human development. Research in Human Development, 5(4), 231-243. https://doi. org/10.1080/15427600802493973.

Eccles, J. S., \& Wigfield, A. (2002). Motivational beliefs, values, and goals. Annual Review of Psychology, 53, 109-132. https://doi. org/10.1146/annurev.psych.53.100901.135153.

Elder, G. H. J. (1994). Time, human agency, and social change: Perspectives on the life course. Social Psychology Quarterly, 57, 4-15.

Elder, G. H., Shanahan, M. J., \& Jennings, J. A. (2015). Human development in time and place. In M. H. Bornstein, \& T. Leventhal (Eds.), Ecological settings and processes in developmental systems (Vol. 4, pp. 6-54). Hoboken: Wiley.

Esping-Andersen, G. (1990). The three workds of welfare capitalism. Cambridge: Polity Press.

Eurostat. (2017). Educational attainment statistics. http://ec.europa.eu/ eurostat/statistics-explained/index.php/Educational_attainment _statistics. Accessed 12 Feb 2019.

Eurofound. (2013). Young people and temporary employment in Europe. https://www.eurofound.europa.eu/sites/default/files/ ef_files/docs/erm/tn1304017s/tn1304017s.pdf.

Evans, K. (2002). Taking control of their lives? Agency in young adult transitions in England and the New Germany. Journal of Youth Studies, 5, 245-271.

Franceschelli, M., Evans, K., \& Schoon, I. (2016). 'A fish out of water?' The therapeutic narratives of class change. Current Sociology, 64(3), 353-372. https://doi.org/10.1177/0011392115595064

Freund, A. M., \& Baltes, P. B. (2000). The orchestration of selection, optimization and compensation: Anaction-theoretical conceptualization of a theory of developmental regulation. In W. J. Perrig \& A. Grob (Eds.), Control of human behavior, mental processes, and consciousness: Essays in honor of the 60th birthday of August Flammer (pp. 35-58). Mahwah, NJ: Lawrence Erlbaum Associates.

Fuchs, S. (2001). Beyond agency. Sociological Theory, 19(1), 24-40.

Hall, D. T. (2004). The protean career: A quarter-century journey. Journal of Vocational Behavior, 65(1), 1-13. https://doi. org/10.1016/j.jvb.2003.10.006.

Heckhausen, J. (1999). Developmental regulation in adulthood: Agenormative and socio-structural constraints as adaptive challenges. New York: Cambridge University Press.

Heckhausen, J. (2010). Globalization, social inequality, and individual agency in human development: Social change for better or worse? In R. K. Silbereisen \& X. Chen (Eds.), Social change and human development: Concepts and results (pp. 148-163). London: Sage.

Heckhausen, J. (2018). The motivation of developmental regulation. In J. Heckhausen \& H. Heckhausen (Eds.), Motivation and action (pp. 741-778). New York, NY: Springer International.

Heckhausen, J., \& Buchmann, M. (2018). A multi-disciplinary model of life-course canalization and agency. Advances in Life Course Research. https://doi.org/10.1016/j.alcr.2018.09.002.

Heckhausen, J., Chang, E., Greenberger, E., \& Chen, C. (2013). Striving for educational and career goals during the transition after high school: What is beneficial? Journal of Youth and Adolescence, 42, 1385-1398.

Heckhausen, J., \& Chang, E. S. (2009). Can ambition help overcome social Inequality in the transition to adulthood? Individual agency and societal opportunities in Germany and the United States. Research in Human Development, 6(4), 235-251. https ://doi.org/10.1080/15427600903281244.

Heckhausen, J., \& Heckhausen, H. (2018). (Eds.). Motivation and action. New York: Springer.

Heckhausen, J., \& Shane, J. (2015). Social mobility in the transition to adulthood: Societal opportunities and constraints for individual agency. In L. A. Jensen (Ed.), The oxford handbook of human development and culture (pp. 535-553). New York, Oxford University Press.

Heckhausen, J., \& Wrosch, C. (2016). Challenges to developmental regulation across the life course: What are they and which individual differences matter? International Journal of Behavioral Development, 40, 145-150.

Heckhausen, J., Wrosch, C., \& Schulz, R. (2010). A motivational theory of life-span development. Psychological Review, 117(1), 32-60. https://doi.org/10.1037/a0017668.

Heckhausen, J., Wrosch, C., \& Schulz, R. (2019). Agency and motivation in adulthood and old age. Annual Review of Psychology 70, 13.1-13.27.

Heckman, J. J., \& Kautz, T. (2012). Hard evidence on soft skills. Labour Economics, 19(4), 451-464. https://doi.org/10.1016/j. labeco.2012.05.014

Hillmert, S., \& Jacob, M. (2010). Selections and social selectivity on the academic track: A life-course analysis of educational attainment in Germany. Research in Social Stratification and Mobility, 28(1), 59-76. https://doi.org/10.1016/j.rssm.2009.12.006.

Hitlin, S., \& Elder, G. H. Jr. (2007). Time, self, and the curiously abstract concept of agency. Sociological Theory, 25(2), 170-191. https://doi.org/10.1111/j.1467-9558.2007.00303.x.

Hitlin, S., \& Johnson, M. K. (2015). Reconceptualizing agency within the life course: The power of looking ahead. American Journal of Sociology, 120(5), 1429-1472. https://doi.org/10.1086/681216.

Hodkinson, P., \& Sparkes, A. C. (1997). Careership: A sociological theory of career decision making. British Journal of Sociology of Education, 18(1), 29-44. https://doi.org/10.1080/0142569970 180102.

Holtmann, A., Menze, L., \& Solga, H. (2017). Persistent disadvantages or new opportunities? The role of agency and structural constraints for low-achieving adolescents' school-to-work transitions. Journal of Youth and Adolescence, 46(10), 2091-2113. https://doi.org/10.1007/s10964-017-0719-z.

Johnson, M. K., \& Reynolds, J. R. (2013). Educational expectation trajectories and attainment in the transition to adulthood. Social Science Research, 42(3), 818-835. https://doi.org/10.1016/j.ssres earch.2012.12.003.

Lerner, R. M., \& Busch-Rossnagel, N. A. (Eds.). (1981). Individuals as producers of their development: A life-span perspective. New York: Academic Press.

Levy, R., \& Buhlmann, F. (2016). Towards a socio-structural framework for life course analysis. Advances in Life Course Research, 30, 30-42. https://doi.org/10.1016/j.alcr.2016.03.005.

Lewin, K. (1943). Defining the 'field at a given time'. Psychological Review, 50, 292-310. https://doi.org/10.1037/h0062738.

Lewin, K., Dembo, T., Festinger, L., \& Sears, P. S. (1944). Level of aspiration. In J. McHunt (Ed.), Personality and the behavior disorders (Vol. 1, pp. 333-378). New York: Ronald.

Loyal, S., \& Barnes, B. (2001). 'Agency' as a red hering. Philosophy of the Social Sciences, 31(4), 507-524.

Marsh, H. W., Trautwein, U., Lüdtke, O., Baumert, J., \& Koller, O. (2007). The big-fish-little-pond effect: Persistent negative effects of selective high schools on self-concept after graduation. American Educational Research Journal, 44(3), 631-669. https://doi. org/10.3102/0002831207306728.

Moffitt, T. E., Arseneault, L., Belsky, D., Dickson, N., Hancox, R. J., Harrington, H., Caspi, A. (2011). A gradient of childhood self-control predicts health, wealth, and public safety. Proceedings of the National Academy of Sciences of the United States of America, 108(7), 2693-2698. https://doi.org/10.1073/pnas.10100 76108.

Mortimer, J. T. (2003). Becoming adult: How teenagers prepare for the world of work. Social Forces, 82(1), 413-415. https://doi. org/10.1353/sof.2003.0101. 
Mortimer, J. T., Zhang, L., Hussemann, J., \& Wu, C.-Y. (2014). Parental economic hardship and children's achievement orientations. Longitudinal and Life Course Studies, 5, 105-128.

Ng-Knight, T., \& Schoon, I. (2017). Can locus of control compensate for socioeconomic adversity in the transition from school to work? Journal of Youth and Adolescence, 6(10), 2114-2128. https://doi.org/10.1007/s10964-017-0720-6.

OECD. (2019). Youth unemployment rate (indicator). https://doi. org/10.1787/c3634df7-en. Accessed 25 Jan 2019.

OECD. (2015), Skills for social progress: The power of social and emotional skills, OECD skills studies. Paris: OECD Publishing. https://doi.org/10.1787/9789264226159-en.

Raffe, D. (2008). The concept of transition system. Journal of Education and Work, 21(4), 277-296. https://doi.org/10.1080/13639 080802360952 .

Reynolds, J. R., Burge, S. W., Robbins, C. L., Boyd, E. M., \& Harris, B. (2007). Mastery and the fulfillment of occupational expectations by midlife. Social Psychology Quarterly, 70(4), 366-383.

Reynolds, J. R., \& Johnson, M. K. (2011). Change in the stratification of educational expectations and their realization. Social Forces, 90(1), 85-109.

Rosenbaum, J. (2001). Beyond college for all: Career paths for the forgotten half. New York: Russel Sage Foundation.

Ross, C. E., \& Mirowsky, J. (2006). Sex differences in the effect of education on depression: Resource multiplication or resource substitution? Social Science \& Medicine, 63, 1400-1413.

Salmela-Aro, K. (2017). Dark and bright sides of thriving - school burnout and engagement in the Finnish context. European Journal of Developmental Psychology, 14(3), 337-349. https://doi. org/10.1080/17405629.2016.1207517.

Savickas, M. L., Nota, L., Rossier, J., Dauwalder, J. P., Duarte, M. E., Guichard, J., van Vianen, A. E. M. (2009). Life designing: A paradigm for career construction in the 21st century. Journal of Vocational Behavior, 75(3), 239-250. https://doi.org/10.1016/j. jvb.2009.04.004.

Schoon, I. (2007). Adaptations to changing times: Agency in context. International Journal of Psychology, 42(2), 94-101. https://doi. org/10.1080/00207590600991252.

Schoon, I. (2010). Planning for the future: Changing education expectations in three British cohorts. Historical Social Research-Historische Sozialforschung, 35(2), 99-119.

Schoon, I. (2012). Planning for the future in times of social change. Child Development Perspectives, 6(4), 335-341. https://doi. org/10.1111/cdep.12003.

Schoon, I. (2014). Parental worklessness and the experience of NEET among their offspring. Evidence from the Longitudinal Study of Young People in England (LSYPE). Longitudinal and Life Course Studies, 6(6), 129-150. https://doi.org/10.14301/1lcs. v5i2.279.

Schoon, I. (2015). Diverse pathways: Rethinking the transition to adulthood. In P. R. Amato, A. Booth, S. McHale, \& J. Van Hook (Eds.), Families in an era of increasing inequality. Diverging destinies (pp. 115-136). London: Springer.

Schoon, I., \& Bynner, J. (Eds.). (2017). Young people's development and the Great Recession: Uncertain transitions and precarious futures. Cambridge: Cambridge University Press.

Schoon, I., \& Bynner, J. (2019). Young people and the Great Recession: Variations in the school-to-work transition in Europe and the United States. Longitudinal and Life Course Studies, 10(2).

Schoon, I., Bynner, J., Joshi, H., Parsons, S., Wiggins, R. D., \& Sacker, A. (2002). The influence of context, timing, and duration of risk experiences for the passage from childhood to midadulthood. Child Development, 73(5), 1486-1504.

Schoon, I., \& Lyons-Amos, M. (2016). Diverse pathways in becoming an adult: The role of structure, agency and context. Research in Social Stratification and Mobility, 46, 11-20. https://doi. org/10.1016/j.rssm.2016.02.008.

Schoon, I., \& Lyons-Amos, M. (2017). A socio-ecological model of agency: The role of structure and agency in shaping education and employment transitions in England. Longitudinal and Life Course Studies, 8(1), 35-56. https://doi.org/10.14301/llcs. v8i1.404.

Schoon, I., \& Mortimer, J. (2017). Youth and the Great Recession: Are values, achievement orientation and outlook to the future affected?. International Journal of Psychology, 52(1), 1-8.

Schoon, I., \& Parsons, S. (2002). Teenage aspirations for future careers and occupational outcomes. Journal of Vocational Behavior, 60(2), 262-288. https://doi.org/10.1006/jvbe.2001.1867.

Schoon, I., \& Polek, E. (2011). Teenage career aspirations and adult career attainment: The role of gender, social background and general cognitive ability. International Journal of Behavioral Development, 35(3), 210-217. https://doi.org/10.1177/01650 25411398183.

Settersten, J. R. A., Gannon, L. (2005). Structure, agency, and the space between: On the challenges and contradictions of a blended view of the life course. Advances in Life Course Research, 10, 35-55.

Shanahan, M. J. (2000). Pathways to adulthood in changing societies: Variability and mechanisms in life course perspective. Annual Review of Sociology, 26, 667-692.

Shanahan, M. J., Bauldry, S., Roberts, B. W., Macmillan, R., \& Russo, R. (2014). Personality and the reproduction of social class. Social Forces, 93(1), 209-240. https://doi.org/10.1093/sf/sou050.

Shane, J., \& Heckhausen, J. (2012). Career-related goal pursuit among post-high school youth: Relations between personal control beliefs and control strivings. Motivation and Emotion, 36, 159-169.

Shane, J., \& Heckhausen, J. (2013). Motivational self-regulation in the work domain: Congruence of individuals' control striving and the control potential in their developmental ecologies. Research in Human Development, 9, 337-357.

Shane, J., \& Heckhausen, J. (2013). University students' causal conceptions about social mobility: Diverging pathways for believers in personal merit and luck. Journal of Vocational Behavior, 82, $10-19$.

Shane, J., \& Heckhausen, J. (2016). For better or worse: Young adults' opportunity beliefs and motivational self-regulation during career entry. International Journal of Behavioral Development, 40, 107-116.

Standing, G. (2011). The precariat: The new dangerous class. London: Bloomsbury.

Steinhoff, A., \& Buchmann, M. (2017). Co-development of academic interest and effortful engagement andits role for educational attainment in a tracked school system. Research in Human Development, 14(2), 122-142. https://doi.org/10.1080/15427 609.2017.1305810.

SuttonTrust. (2017). The state of social mobility in the UK. https:// www.suttontrust.com/wp-content/uploads/2017/07/BCGSocialMobility-report-full-version_WEB_FINAL-1.pdf. Accessed 14 Feb 2019.

Tolman, E. C. (1932). Purposive behavior in animal and men. New York: Appleton-Century.

Tomasik, M. J., \& Salmela-Aro, K. (2012). Knowing when to let go at the entrance to university: Beneficial effects of compensatory secondary control after failure. Motivation and Emotion, 36(2), 170-179. https://doi.org/10.1007/s11031-011-9246-5.

Villarreal, B. J., Heckhausen, J., Lessard, J., Greenberger, E., \& Chen, C. (2015). High-school seniors' short-term educational expectations: Do the costs of failing one's expectations outweigh the benefits of ambitious expectations? Journal of Adolescence, 45, $327-340$. 
Vuolo, M., Staff, J., \& Mortimer, J. T. (2012). Weathering the Great Recession: Psychological and behavioral trajectories in the transition from school to work. Developmental Psychology, 48(6), 1759-1773. https://doi.org/10.1037/a0026047.

Walther, A. (2006). Regimes of youth transitions: Choice, flexibility and security in young people's experiences across different European contexts. Young, 14(2), 119-139. https://doi. org/10.1177/1103308806062737.

Wrosch, C., \& Heckhausen, J. (1999). Control processes before and after passing a developmental deadline: Activation and deactivation of intimate relationship goals. Journal of Personality and Social Psychology, 77, 415-427.

Publisher's Note Springer Nature remains neutral with regard to jurisdictional claims in published maps and institutional affiliations. 